\title{
How Much To Ask? Platforms, Parties, and Suggested Amounts in Political Fundraising
}

\author{
Seo-young Silvia Kim* \\ American University
}

October 17, 2021

\begin{abstract}
How much do political campaigns ask for contributions, and how do they vary by electoral characteristics and fundraising environments? When soliciting donations, campaigns typically present a set of suggested amounts to procure more money from potential donors. However, we know almost nothing about how campaigns make these demand-side choices. This paper builds benchmark observations and analyzes how political parties and fundraising platforms shape these decisions, using data collected from U.S. federal candidates and fundraising platforms in 2020. Candidates' average suggested amounts differ by party, state-level average income, and fundraising platforms. Ideologically extreme candidates did not solicit smaller dollars, and if anything, the opposite was documented. In addition, the representative digital fundraising platforms by party-ActBlue for Democrats, WinRed for Republicans—could influence campaign tactics such as effective, top-down adjustment for increased contribution limits. I conclude that platforms can be important, active players in the campaign finance ecosystem.
\end{abstract}

\section{Abstract}

Word Count: 8,984

\footnotetext{
${ }^{*} \mathrm{Kim}$ is an Assistant Professor at American University and is the corresponding author (email: sskim@american.edu). I thank Jeff Gill, Candace Nelson, and Josh Kalla for their comments. An earlier version of this paper was presented in APSA 2021 Pre-conference: Frontiers of Money in Politics Research.
} 
How much do political campaigns ask for contributions, and how do they vary by electoral characteristics and fundraising environment? The campaign finance literature is heavily focused on the supply side, or to whom do individuals and political action committees give and why. However, equally important is the demand side-how do campaigns approach and solicit money from potential contributors, and how do they vary by electoral characteristics and fundraising environments?

This paper builds benchmark observations about what preset suggested amounts campaigns show to potential donors, using data collected from U.S. federal candidates and fundraising platforms in 2020. I find that not only are they dependent on characteristics such as parties, but digital fundraising platforms, which were typically regarded as background infrastructure that supports donors and campaigns, can make active choices that shape campaign behavior.

Previous literature has established that campaigns attempt to maximize donations by depending on habitual or repeat donors (Francia et al., 2003; Hassell and Monson, 2014; Heerwig, 2016) and varying campaign messages to activate different motivations (Hassell and Monson, 2014; Miller et al., 2016). However, no research has yet to document the set of amounts political campaigns suggest to potential donors and why. To put it another way: why would a candidate $A$ be asking for ten dollars, while a candidate $B$ asks for a hundred or even thousands of dollars?

This gap is in the literature puzzling-American elections are a multi-billion dollar industry smashing record every election cycle and exceeding \$14 billion in 2020, more than double the previous cycle. Just as Doctors Without Borders or The Salvation Army do, a campaign reaches out with a set of options with varying amounts. Besides, a series of well-established literature exists about how framing and nudging affect human behavior, such as charitable giving in social psychology, marketing, and decision sciences.

There are, of course, crucial distinctions between money in politics and for-profit or nonprofit marketing. Every political campaign is embedded in the fabric of partisanship, issue salience, electoral calculations, and networks of political organizations such as parties. Based on the assumption that campaigns have a logical reason to optimize suggested amounts, such decisions may vary by important characteristics-in the case of candidate campaigns-such as incumbency, party, ideological extremism, and the choice of digital fundraising platforms.

I find that candidates' average suggested amounts differ by characteristics such as party, statelevel average income, electoral safety, and fundraising platforms. The average suggested amount, while it depends on state-level per capita income, was about \$200 higher for Republican candidates. Using major digital fundraising platforms (ActBlue for Democrats, WinRed for Republicans) was associated with a significantly lower average suggested amount. Ideologically extreme candidates did not solicit smaller dollars, which provides a complementary set of intuition for scholarly debate on whether small donors are more polarizing.

In particular, I argue that digital fundraising platforms affect campaigns' behavior, based on the 
data collected on American federal races in the 2020 cycle. Two representative digital fundraising platforms correspond to the two parties: ActBlue for the Democratic Party and WinRed for the Republican Party. They may seem like passive players in the campaign finance ecosystem, but their decisions can affect fundraisers in surprising ways, which in turn has the potential to spill over into individual campaign contributors' behavior. The platforms both seem to respectively have internal playbooks with default sets of preset amounts that they recommend to a new entrant, which strongly determines the distribution of suggested amounts.

Moreover, I find that WinRed helped its hosted fundraisers adjust their suggested amounts to account for the increased FEC individual contribution limit almost immediately, while ActBlue did not. This shows a strong top-down management tactic as opposed to ActBlue, possibly stemming from the strong party affiliation of WinRed. The results show that platforms can also be important, active players in the campaign finance ecosystem, affecting how effectively campaigns optimize their fundraising endeavors.

The findings show that demand-side campaign behavior may be a source of omitted variable bias in our understanding of how fundraising outcomes are determined. How campaigns appeal to potential donors are surprisingly heterogeneous and determined by various electoral characteristics and fundraising environments. Although it remains to be seen whether campaigns' solicitation techniques are optimal, the results can potentially provide intuitions for a variety of research topics, including (1) analyzing how campaigns perceive their financial electorate (Fenno, 1978), (2) statistical anomaly detection in individual contribution patterns (Tam Cho and Gaines, 2007), and (3) how political and charitable giving may differ. Finally, the effect of campaign behaviors may be amplified in future elections, as reliance on small dollars has proven to be a somewhat viable strategy (Alvarez et al., 2020), and the online frenzy for campaign cash intensifies, especially with decreased in-person fundraisers post-COVID. In particular, the platforms may broaden the median voter's political participation scope, moving away from the traditional model where only the economically privileged donated to campaigns.

\section{The Tale of the Two Fundraising Platforms}

To understand how digital fundraising platforms came to be, some background must be established. As reforms of the Bipartisan Campaign Reform Act of 2002 (BCRA) crumbled and presidential campaigns moved away from public funding, the need to raise more intensified.

This need for cash went hand-in-hand with the digitization of campaigns. Howard Dean's presidential race in 2004 is often accredited as the "first digital campaign" (Hindman, 2005), but donors were able to donate online to presidential campaigns in 2000 as well. The Obama campaign in 2008 garnered more attention with its use of the Internet, raising more than $\$ 778$ million and appealing to small donors at the same time.

By this time, ActBlue, established in 2004, had already raised 24 million by its third anniversary 
for thousands of Democratic candidates. Obama did not link its campaign website to an ActBlue referral (Helman, 2007) but instead relied on its own grassroots network for fundraising. However, DCCC linked potential donors to ActBlue for its most vulnerable candidates (Herrnson and Curtis, 2011). All in all, ActBlue was speedily increasing its presence.

ActBlue describes itself as the "home of small-dollar donors," where fundraising tools that reach grassroots donors are available. Indeed, while the Clinton campaign in the 2016 presidential race did not use ActBlue, the small-donor success of the Sanders campaign using only ActBlue (Alvarez et al., 2020) was extremely prominent. Sequentially, in the 2020 race, all Democratic presidential campaigns plugged ActBlue into their online website.

ActBlue is several things at once-it is a nonprofit, an intermediary political action committee (PAC) (Alvarez et al., 2020), a digital platform that hosts fundraiser pages for liberal causes (Herrnson and Curtis, 2011; Cigler, 2011), and an immense, central repository of contact information and giving history. Once a donor's data is stored, ActBlue makes it giving as easy as clicking a single button or sending a text, which helps to (1) carry a potential donor over to many recipients as well as (2) encouraging repeat/habitual donations. In the 2008 election cycle, it helped actively direct potential donors to a salient set of candidates. This is in sharp contrast to the present-day ActBlue, which no longer shows a particular candidate or a PAC on its front page-just that it has raised more than 8 billion dollars to date.

The Republicans tried hard to replicate the success of ActBlue, but ABC PAC/Rightroots (Helman, 2007; Cigler, 2011), Big Red Tent (Vogel, 2007), Slatecard.com (Vogel, 2007), and ActRight (Smith, 2010; Willis, 2014) all eventually failed and disappeared. Although how they attempted to operate was varied, none of these were very successful. By late 2018, but the platform choices were still fragmented between "half-dozen [for-profit processing] such vendors servicing Republican candidates and committees" (Saul and Shorey, 2019). Some strong contenders were Anedot's GIVE.GOP (established in 2010), Revv (2014), Targeted Victory's Victory Passport (2013), and Campaign Solutions (1998).

Eventually, GOP leaders forcibly resolved this coordination game on fundraising platforms during the Trump administration. The Trump campaign, which had used Victory Passport in 2015, made an abrupt switch to Revv in 2016. There were reports that the campaign moved to blacklist vendors that worked with Trump's rivals and "Never Trumpers" (Vogel and Schreckinger, 2016; Vogel and Samuelsohn, 2016). The platform was eventually named WinRed and launched in 2019 under Trump and GOP leaders' supervision. Indeed, the launch was officially announced and endorsed by the Trump campaign, which was again advertised on the website (see Appendix).

By mid-2019, RNC had made it clear that it intended to shut down all of WinRed's competitors and urged candidates to switch to the party-created platform. For example, Give.GOP, which had also launched in 2019 had been prohibited from using the GOP domain and RNC's logo (Isenstadt, 2019). At the same time, the RNC chief of staff announced that "consistent with 


\begin{tabular}{lrr}
\hline & ActBlue & WinRed \\
\hline Type & Conduit/non-profit & Conduit/for-profit \\
Ideology & Liberal & Conservative \\
Established Year & 2004 & 2019 \\
Creation/Endorsement from Party & No & Yes \\
Uses Party's National Voter Files & No & Yes \\
\hline
\end{tabular}

Table 1: Comparison of ActBlue and WinRed

RNC policy of using technology to support the Republican Party as a whole, [RNC] will only invest in federal candidates and state parties that use RNC data and the WinRed platform." RSLC president claimed that Give.GOP was a predatory scheme. Give.GOP changed its name to Right.us and continued, but dwindled.

Just like ActBlue, WinRed is an intermediary PAC, also known as a conduit, meaning that it is a vendor passing along donors' contributions, subject to a platform-specific fee. All of such transactions will be available as FEC public records even if the amounts are under the usual \$200 disclosure threshold (Alvarez et al., 2020).

But there are critical differences between ActBlue and WinRed. ActBlue is a nonprofit, and WinRed is for-profit. WinRed is a merge between a fundraising platform and the party's voter data (DataTrust), while ActBlue is not. But the most important distinction is the degree to which the respective party endorses and pushes the platform usage. ActBlue's growth was more gradual, and the platform is open to all Democratic or progressive candidates and causes. The Democratic Party, although recognizing its potential (e.g., DCCC adding referral links to ActBlue in 2008), did not explicitly encourage or require that its candidates use ActBlue. ${ }^{1}$ ActBlue was an ally but not a party ploy. ${ }^{2}$ WinRed is effectively another branch of the Republican Party.

Table 1 summarizes the differences between ActBlue and WinRed. Setting aside their asymmetric roles, there is no doubt that ActBlue and WinRed are now the two parties' dominant fundraising platforms. WinRed's final FEC report for the 2019-2020 election cycle shows 2 billion in total individual contributions; ActBlue's 4.3 billion. Not only do these numbers show that digital fundraising is a rapidly growing, powerful force, but that platforms' roles in today's politics are not to be underestimated and warrant a detailed analysis.

\footnotetext{
${ }^{1}$ ActBlue itself has continuously emphasized its importance to the party. For example, in its third-anniversary blog post, it wrote "ActBlue is an investment in our Party. ActBlue is an investment in a Democratic future."

${ }^{2}$ Other such example of ally-organizations is Catalist, which compiles voter data for Democrats and progressives, and MoveOn, which focuses on activism and advocacy.
} 


\section{Fundraising Platforms, Digital Technology, and Small Donors}

Two distinct branches of literature have noted the advent of digital fundraising platforms. Researchers in political communication and information technology have noticed ActBlue as one of the infrastructures in sustaining mobilization campaigns and activism. Researchers in campaign finance have noted how they fuel the small-dollar movement. Both lines of literature have focused exclusively on ActBlue because prior to 2019, WinRed did not exist.

Platforms as Infrastructure. Karpf (2012) notes that ActBlue is a form of technological infrastructure that operates in the background for grassroots organizations. ActBlue plays a complementary role to membership-based political organizations by outsourcing the cumbersome work of online fundraising and lowering overhead costs (Magleby et al., 2018). Indeed, ActBlue is a stereotypical example of organizations in the analytic activism (Karpf, 2016a) ecosystem because (1) A/B testing is frequently deployed at the platform level, (2) since the late 2010s, individual fundraisers were encouraged to make use of the testing capabilities, and (3) fundraising success is by nature easily measurable. Fundraising platforms could also be viewed as what Kreiss (2019) calls digital opportunity structures.

The literature also notes how the Republican Party lagged behind the Democratic party in building and maintaining technological infrastructures for their campaigns. Karpf (2013), BaldwinPhilippi (2015), and Karpf (2016b) report the partisan technology gap, where the Republican Party attempted their own versions of ActBlue, MoveOn, and DailyKos, and have failed. Kreiss (2016) shows that such gap between the Democratic and Republican parties were decades in the making, for example, by showing the differential number of tech staffers employed in presidential campaigns starting from 2004. Although WinRed has reasonably caught up with ActBlue through the party's forcible and deliberate coordination efforts, this historical context must be noted to understand the significance of digital fundraising platforms in general.

WinRed, as an infrastructure, is reasonably symmetric to ActBlue. Both enable easier recurring donations and donations across multiple recipients once donors' information is stored in the system. In fact, both ActBlue and WinRed are recently being scrutinized for their recurring donation tactics (Goldmacher, 2021a), although WinRed's more aggressive tactics of pre-checked recurring donation boxes have gained created more alarm, with almost 13 million dollars' worth refunds issued from Trump and the Republican Party committees (Goldmacher, 2021b).

However, how specifically platforms as infrastructure impact campaigns and donor behavior is still lacking in the literature. This paper serves to fill the gap by one particular account of fundraising platforms' impact: the choice of preset suggested amounts in solicitations.

Platforms as Fuel to the Small Donor Movement. In the campaign finance literature, the interest lies more in how platforms can facilitate small-dollar donations and how it may skew 
representation and academic interpretation.

Malbin (2013) described ActBlue as an online pro-Democratic party organization that performs bundling with a focus on competitive races, and wrote "... it is clear that in the current communications environment an ongoing organization brings a capacity to the search for small donors that a new candidate's campaign committee cannot bring on its own." Given that digital fundraising platforms create such opportunities to boost small donations, the question becomes whether they affect representation and what normative implications it brings. Malbin (2013) and McCabe and Heerwig (2019) observe that small donors are more economically representative. Alvarez et al. (2020) documents how, within the Sanders campaign, small donors were more racially diverse and potentially younger. However, another branch of the literature also notes how small donors might (or might not) be more polarizing by supporting ideologically extreme candidates (Bonica, 2011; Magleby et al., 2018; Culberson et al., 2019; Keena and Knight-Finley, 2019). ${ }^{3}$

Enabling small donations can also fuel nationalized campaigns and more opportunities to give to out-district campaigns. This may skew representation in a different direction, strengthening the reliance on inter-district flow of money (Gimpel et al., 2008; Canes-Wrone and Miller, 2021).

Small donors boosted by platforms may even skew our understanding of the individual contributors. Due to the stricter disclosure requirements imposed on conduits, comparing all available FEC transaction records across campaigns may be an apples-to-oranges comparison depending on their varying reliance on fundraising platforms (Alvarez et al., 2020). To prevent the confounding bias from platform usage, only transactions above the $\$ 200$ disclosure cutoff should be compared (Barber et al., 2017, 2019; Alvarez et al., 2020).

Is WinRed symmetric to ActBlue in its emphasis and reliance on small donors? I will demonstrate that this is not necessarily the case by showing the distribution of amounts asked in all WinRedhosted campaigns and comparing it to ActBlue.

Platforms as Part of the Party Structure. Because WinRed is rather a recent invention, the literature has not addressed platforms as part of party structures. As reviewed earlier, ActBlue, while highly beneficial for fundraising, was never strictly under the Democratic Party's umbrella.

However, given WinRed, the scholarship must also speak to how platforms (or just WinRed as of present) are more than just technological infrastructure and relate to party organizations. For the Republican Party, WinRed is both the fruit of cooperation from various party groups (Koger et al., 2010; Bawn et al., 2012) and now another entity in the informal party network and coalition. That is to say, it has evolved into another party-connected organization (Herrnson, 2009) that has been delegated the task of better managing the mass-scale online fundraising.

\footnotetext{
${ }^{3}$ The issue is even more important because the Democratic Party is actively encouraging small-dollar donations as an end. Pildes (2019) documents how DNC has used small-donor participation rates as a filter to prune presidential primary candidates, prompting some candidates to burn money to have small donations on their books. The new For The People Act of 2021 also contains a six-to-one public matching proposal for small dollars.
} 


\section{Data}

\section{Federal Candidates' Official Campaign Websites}

The first data is collected from all U.S. general election candidates' official campaign websites in the 2020 cycle. The data is primarily based on the redirect links for contributions; that is to say, what donors would see if they were attempting to give to candidates from their official campaign websites. After limiting to general election two-party candidates (including a few major Independents such as Bernie Sanders), the full sample consists of 818 House candidates and 148 Senate candidates. While it would have been ideal to have gathered data for all who ran, including unsuccessful primary challengers, collecting primary candidates' data was a daunting task due to the high volume of fringe, nonviable candidates.

The data was collected multiple times throughout the campaign, but for most Senate and House campaigns, the amounts did not change. Therefore, given that candidates enter the race at different points in the campaign, only the cross-sectional snapshot closest to Election Day was used for comparability.

\section{Fundraising Platforms' Directories}

The second dataset is a collection of data from digital fundraising platforms' official directories. ActBlue makes most of its fundraiser pages and entities public at https:/ / secure.actblue.com/directory. WinRed's directory is visible at its front page, https://winred.com. For comparison, I also included the directory from Right.us, which was ousted from the Republican Party.

ActBlue displays all types of fundraisers on its directory, ranging from ballot initiatives, nonprofits by areas (e.g., gun control, reproductive rights), and various candidates at the federal, state, and local elections. Typically, more than 20,000 recipients are listed, and under each entity, fundraiser URLs that support the entity are listed. There are more than 75,000 unique URLs. WinRed, on the other hand, displayed only about 400 federal candidates during the 2020 cycle. Only starting on February 2021 did it start displaying state-level candidates, eventually extending also to local elections.

Suggested amounts were scraped from all available recipients on the directory. Eventually, both datasets were augmented with candidate characteristics such as incumbency and electoral outcomes. As with the first dataset, only the last snapshot closest to Election Day was used.

The second dataset sometimes overlaps with the first dataset. For example, if a Republican candidate directs its potential donors to a WinRed page from its official campaign website, and it is the same URL found from the WinRed directory, the observation is common to both datasets. However, in many cases, they are distinct because campaigns tend to change their redirect URLs depending on the changing electoral context. For more details on referral links, see Appendix. 


\section{How Much Do Campaigns Ask of Donors?}

\begin{tabular}{|c|c|c|c|c|}
\hline & Democrat, Senate & Democrat, House & Republican, Senate & Republican, House \\
\hline No Defaults & $2.7 \%$ & $0.7 \%$ & $0.0 \%$ & $8.0 \%$ \\
\hline Mode of Solicitation Set & $25-100-250-1000$ & $25-100-250-1000$ & $25-50-100-250-500-1000-2800$ & $25-50-100-250-500-1000-2800$ \\
\hline Median of Min. USD Solicited & 10.0 & 20.2 & 25.0 & 25.0 \\
\hline Median of Mean USD Solicited & 498.6 & 620.8 & 675.0 & 675.0 \\
\hline Median of Max. USD Solicited & $2,700.0$ & $2,800.0$ & $2,800.0$ & $2,800.0$ \\
\hline Used Major Platform & $90.7 \%$ & $85.3 \%$ & $63.6 \%$ & $44.9 \%$ \\
\hline Did Not Adjust $\$ 2,700$ & $8.0 \%$ & $3.8 \%$ & $3.0 \%$ & $2.2 \%$ \\
\hline Used \$2,800 (Legal Max.) & $41.3 \%$ & $54.3 \%$ & $86.4 \%$ & $77.8 \%$ \\
\hline Solicited More Than $\$ 2,800$ & $9.3 \%$ & $7.6 \%$ & $33.3 \%$ & $27.4 \%$ \\
\hline Sanders Heritage $(\$ 27)$ & $2.7 \%$ & $3.6 \%$ & $0.0 \%$ & $0.0 \%$ \\
\hline
\end{tabular}

Table 2: Suggested Amounts, Candidates by Chamber and Party, 2020 Election Cycle

Table 2 shows interesting patterns about how different candidates, on average, tend to ask as contributions. Medians over summary statistics are used, as distributions are highly skewed (See Appendix). In addition, the table contains a summary on (1) whether the candidate used the major platform of their party, (2) whether candidates asked for $\$ 2,700$ (unadjusted individual contribution limit from the 2018 Election Cycle), (3) whether candidates asked for \$2,800 (individual contribution limit for the election), (4) whether candidates asked for more than $\$ 2,800$ by asking for a lump contribution for the primary and general race or by asking for a couple's bundled donations, and (5) whether candidates asked for \$27, which is highly associated with campaign strategies of Bernie Sanders (Sen-VT).

Republicans tend to ask for higher amounts on average, regardless of the chamber. In particular, this is driven by their tactics of asking for more than the individual contribution limit of $\$ 2,800$. About a third of Republican Senate candidates and a quarter of Republican House candidates used similar tactics. Democrats in both chambers used such a tactic at most one out of ten cases.

Another interesting pattern is how the amount of \$27, a defining characteristic of the Sanders campaign starting from 2016 (Alvarez et al., 2020), is replicated in some Democratic candidates. Bernie Sander's 2016 campaign repeatedly emphasized the small-donor reliant nature of the campaign. After calculating the average amount given to the campaign as roughly $\$ 27$, the campaign started to offer $\$ 27$ as an amount that donors could choose. The $\$ 27$ is considered his small-donor-based tactic's legacy-it is otherwise an inconspicuous number to ask. Naturally, the DW-NOMINATE scores of Democrats using \$27 are more extreme than those who do not (Welch two-sample $t$-test, one-sided hypothesis, $p$-value $=0.07189) .{ }^{4}$

Table 3 shows some insight into how these amounts are potentially determined in Congressional races by showing a simple ordinary least squares (OLS) regression of suggested amounts on electoral characteristics. While three dependent variables_-minimum, mean, and maximum sug-

\footnotetext{
${ }^{4}$ Note that this is underestimated. First, extreme challengers who lost do not have a DW-NOMINATE score estimated. Second, progressive politicians such as Alexandria Ocasio-Cortez have not been measured as being more liberal—see https:/ / voteview.com/articles/ocasio_cortez.
} 


\begin{tabular}{|c|c|c|c|c|c|c|}
\hline & \multicolumn{6}{|c|}{ Dependent variable: } \\
\hline & $\min$ & $\min$ & mean & mean & $\max$ & $\max$ \\
\hline Senate & $\begin{array}{l}-1.439 \\
(3.139)\end{array}$ & $\begin{array}{l}-1.929 \\
(4.420)\end{array}$ & $\begin{array}{c}33.524 \\
(44.583)\end{array}$ & $\begin{array}{c}34.241 \\
(60.493)\end{array}$ & $\begin{array}{c}148.816 \\
(193.395)\end{array}$ & $\begin{array}{c}137.273 \\
(260.916)\end{array}$ \\
\hline Republican Party & $\begin{array}{l}-14.536 \\
(18.214)\end{array}$ & $\begin{array}{c}4.056 \\
(10.742)\end{array}$ & $\begin{array}{l}192.368^{*} \\
(88.763)\end{array}$ & $\begin{array}{c}266.494^{* *} \\
(102.389)\end{array}$ & $\begin{array}{c}1,132.224^{* * *} \\
(272.022)\end{array}$ & $\begin{array}{c}1,327.867^{* * *} \\
(355.653)\end{array}$ \\
\hline Incumbent & $\begin{array}{l}-0.679 \\
(9.621)\end{array}$ & $\begin{array}{c}13.894^{* * *} \\
(3.361)\end{array}$ & $\begin{array}{c}90.107 \\
(47.190)\end{array}$ & $\begin{array}{c}73.465 \\
(80.769)\end{array}$ & $\begin{array}{c}345.795 \\
(177.175)\end{array}$ & $\begin{array}{c}80.764 \\
(370.781)\end{array}$ \\
\hline Open Seat & $\begin{array}{l}-1.757 \\
(5.606)\end{array}$ & $\begin{array}{c}11.856^{* * *} \\
(3.501)\end{array}$ & $\begin{array}{c}11.126 \\
(40.834)\end{array}$ & $\begin{array}{c}15.850 \\
(94.971)\end{array}$ & $\begin{array}{c}-21.394 \\
(174.448)\end{array}$ & $\begin{array}{l}-251.979 \\
(436.989)\end{array}$ \\
\hline State-level Average Per Capita Income (1,000 USD, 2020) & $\begin{array}{l}0.572^{* *} \\
(0.202)\end{array}$ & $\begin{array}{l}0.607^{*} \\
(0.274)\end{array}$ & $\begin{array}{l}5.396^{* *} \\
(1.680)\end{array}$ & $\begin{array}{l}6.455^{*} \\
(2.585)\end{array}$ & $\begin{array}{l}15.425^{*} \\
(6.514)\end{array}$ & $\begin{array}{c}18.926^{*} \\
(9.540)\end{array}$ \\
\hline Electoral Safety Based On Cook PVI & $\begin{array}{c}0.210 \\
(0.266)\end{array}$ & $\begin{array}{l}-0.025 \\
(0.204)\end{array}$ & $\begin{array}{c}1.029 \\
(1.412)\end{array}$ & $\begin{array}{l}-3.313 \\
(2.164)\end{array}$ & $\begin{array}{l}3.145 \\
(5.204)\end{array}$ & $\begin{array}{c}-17.872^{*} \\
(8.260)\end{array}$ \\
\hline Used ActBlue & $\begin{array}{l}-21.986 \\
(17.176)\end{array}$ & $\begin{array}{c}-5.515 \\
(11.399)\end{array}$ & $\begin{array}{c}-196.615^{*} \\
(80.997)\end{array}$ & $\begin{array}{c}-193.159^{*} \\
(95.883)\end{array}$ & $\begin{array}{c}-665.320^{* *} \\
(217.071)\end{array}$ & $\begin{array}{c}-759.948^{* *} \\
(274.122)\end{array}$ \\
\hline Used WinRed & $\begin{array}{c}-10.195^{* *} \\
(3.637)\end{array}$ & $\begin{array}{c}-11.714^{*} \\
(5.693)\end{array}$ & $\begin{array}{c}-108.691^{*} \\
(50.657)\end{array}$ & $\begin{array}{c}-167.726^{*} \\
(71.631)\end{array}$ & $\begin{array}{l}-301.833 \\
(226.900)\end{array}$ & $\begin{array}{l}-512.261 \\
(310.528)\end{array}$ \\
\hline Ideological Extremity Based On DW-NOMINATE & & $\begin{array}{l}-12.090 \\
(46.343)\end{array}$ & & $\begin{array}{l}-211.257 \\
(300.359)\end{array}$ & & $\begin{array}{l}-656.328 \\
(895.023)\end{array}$ \\
\hline Ideological Extremity $\times$ Republican Party & & $\begin{array}{c}22.805 \\
(47.710)\end{array}$ & & $\begin{array}{c}664.639 \\
(392.968)\end{array}$ & & $\begin{array}{c}2,866.030 \\
(1,465.557)\end{array}$ \\
\hline Observations & 927 & 532 & 927 & 532 & 927 & 532 \\
\hline $\mathrm{R}^{2}$ & 0.033 & 0.025 & 0.134 & 0.108 & 0.167 & 0.155 \\
\hline Adjusted $\mathrm{R}^{2}$ & 0.024 & 0.006 & 0.126 & 0.091 & 0.159 & 0.138 \\
\hline
\end{tabular}

Table 3: Relationship Between Electoral Characteristics and Minimum, Mean, and Maximum Suggested Amounts

gested amounts-are presented as key summary statistics, the variance for both the minimum and the maximum amounts are lower. Therefore, the mean suggested amount is the most relevant and informative dependent variable. The sample excludes three Independents and those who did not have explicit amounts solicited. Electoral safety is calculated from Cook PVI measures, and ideological extremity is calculated based on deviations of DW-NOMINATE scores from the party's average, with larger value indicating a more ideologically extreme candidate. ${ }^{5}$ Because DW-NOMINATE is not available for unsuccessful challengers and open-seat candidates, models with and without the extremity measure (respectively limited and full sample) are shown.

Some key candidate and election-specific variables were surprisingly not relevant for predicting the mean suggested amount, such as whether the candidate was for the Senate/House or the candidate's incumbency status. Across all dependent variables, Senate was not significant. Compared to being a challenger, being an incumbent or an open-seat candidate increased the minimum value solicited, but only after controlling for ideological extremity - which gets rid of most challengers and open-seat candidates-and not by very much.

\footnotetext{
${ }^{5}$ Naturally the two are highly correlated, with a Pearson's correlation coefficient of 0.4537 ( $p$-value $\left.<0.001\right)$.
} 


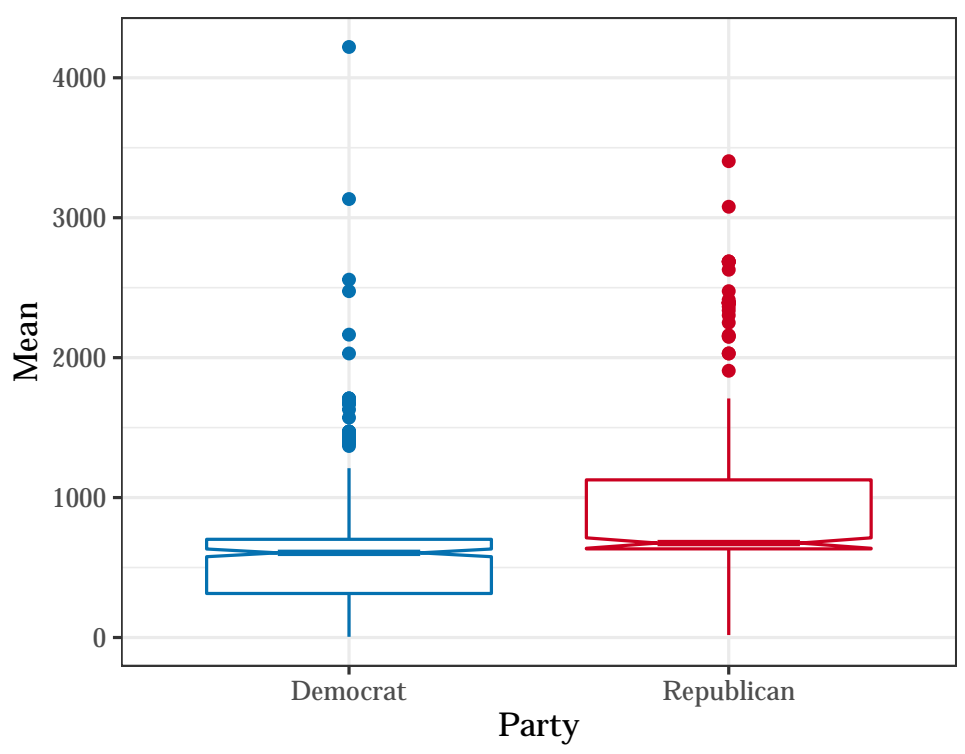

Figure 1: Boxplot of Mean Solicited Amount by Party

On the other hand, being a Republican candidate lead to a significantly large increase in the average suggested amount. Figure 1 shows the notched box plots by party. In the full sample, the Republican Party is associated with nearly a $\$ 200$ increase. This jump is driven by including much larger amounts as maximum values in the preset amounts. Note how in Table 2, the modal Republican candidate asked for $\$ 2,800$, the individual contribution limit, while the modal Democratic candidate only asked up to $\$ 1,000$.

The state-level average per capita income is also associated with higher suggested amounts, an intuitive result. Of course, research finds that two-thirds of funding comes from outside the district (Gimpel et al., 2008), but given that a significant portion of candidates' financial electorate is still within the state, the amounts would need to be tailored to the state's average income level. Table 3 shows that across all dependent variables, the state's income level is significant.

In addition, using the major platforms is associated with smaller contribution amounts asked. This is true for both Republicans using WinRed and Democrats using ActBlue for the mean value of suggested amounts. For Democrats using ActBlue, this seems driven by significantly smaller maximum amounts implemented, while for WinRed, this is not the case-rather, the minimum suggested amount is lowered.

What is interesting is ideological extremity. If small donors tend to fuel ideologically extreme candidates, then it is likely that extreme candidates' campaigns understand this and actively seek out smaller dollar donations and offer smaller sets of suggested amounts. However, among candidates with a DW-NOMINATE score, there is no such evidence. In fact, if anything, it is the opposite-extreme Republican candidates seem to be asking for significantly larger maximum amounts, while for Democrats, there is no significance. For a bivariate distribution, see Figure 2. 


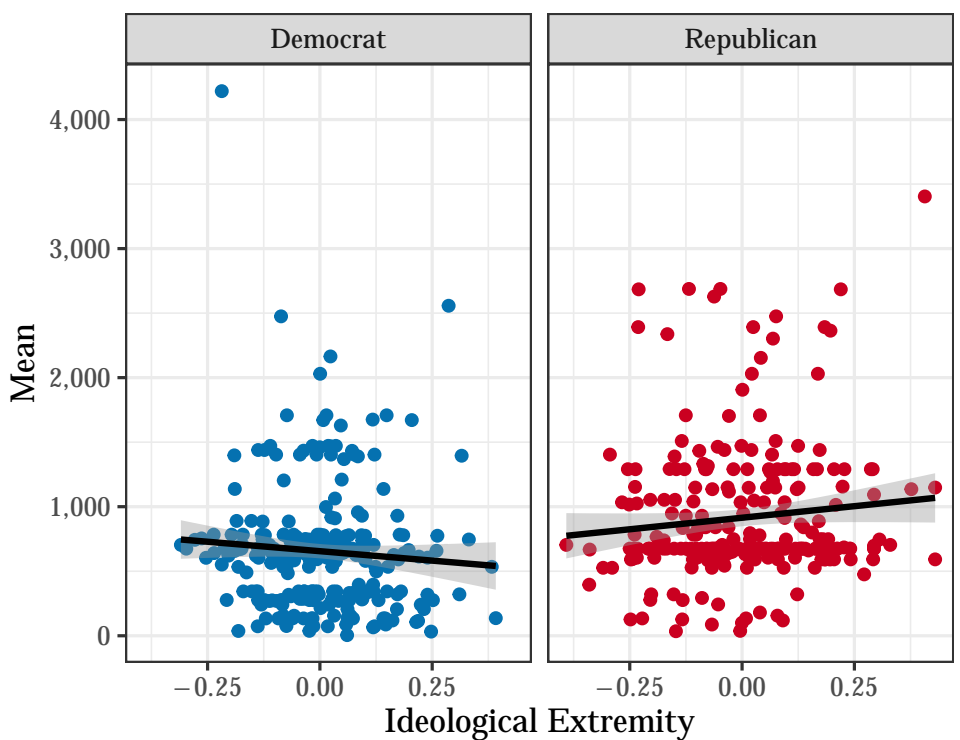

Figure 2: Scatterplot of Ideological Extremity and Mean Solicited Amount by Party

\section{The Effect of Platforms on Campaign Fundraising Tactics}

\section{Default Set of Suggested Amounts}

We have already seen that using ActBlue and WinRed were associated with lower preset suggested amounts for the respective party's candidates. Is this a coincidence? Figure 5 shows that this is not. Depending on the platform used, candidates demonstrate a very different distribution of suggested amounts.

The first notable trend is how candidates depending on minor platforms have higher probabilities of showing no suggested amounts at all. ${ }^{6}$ Another notable trend is how, especially among Democratic candidates, the maximum amount suggested is much higher for candidates using minor platforms. Finally, more than $40 \%$ of Republicans have chosen to use the same set of suggested amounts. The last observation, in particular, suggests that there may be overarching guidance on what suggested amounts to use as campaign tactics.

To check whether the platform provides any guidelines, I draw the same plots but for all candidates on the platform directories in Figure 4. The figure shows that save for the Right.us, both ActBlue and WinRed have very skewed distributions. A set of 25-100-250-1,000 USD, the modal set in ActBlue, consists $41.7 \%$ of all its pages in its directory, which includes primary candidates, state-level and local-level candidates, and other non-candidate fundraisers. Suggested amounts of 25-50-100-250-500-1,000-2,800 USD, the modal set in WinRed, consists $48.5 \%$ of all its pages in its directory, which now includes unsuccessful primary candidates.

\footnotetext{
${ }^{6}$ Note that these candidates were excluded from Table 3.
} 

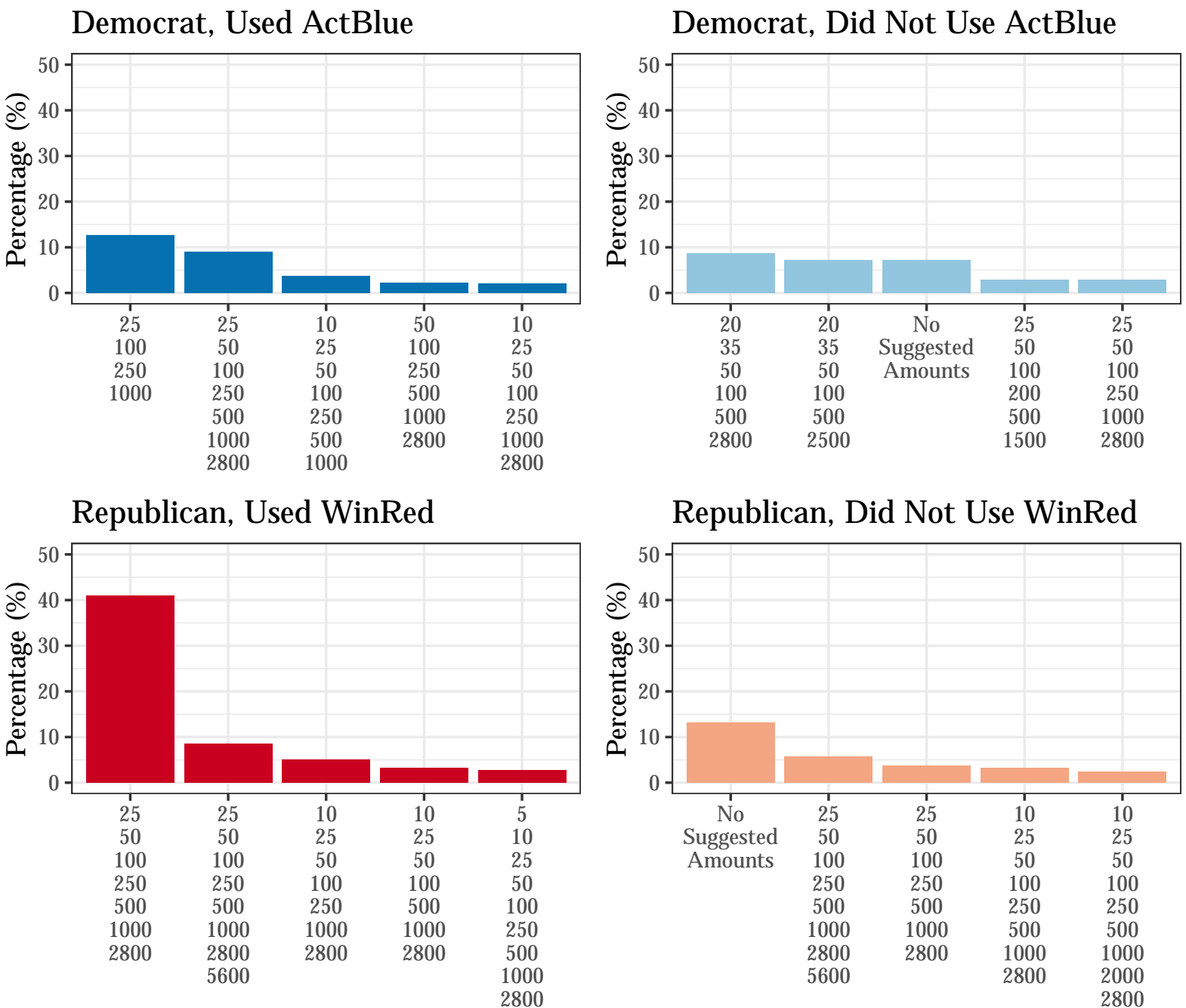

Figure 3: Suggested Amounts, Top 5 Sets Per Party/Platform, 2020 Congressional General Candidates 


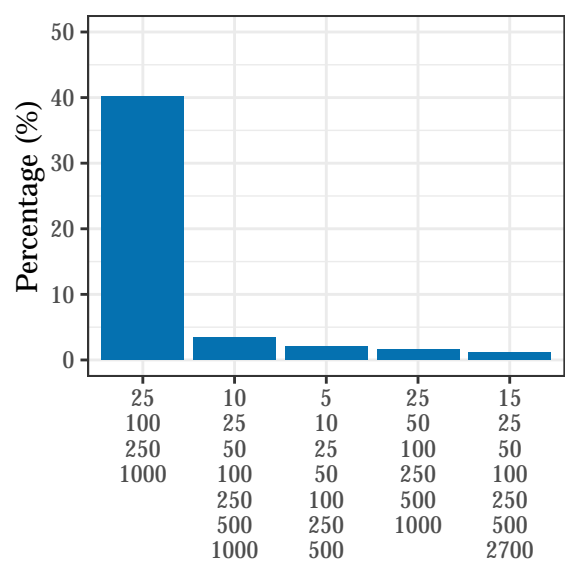

(a) ActBlue

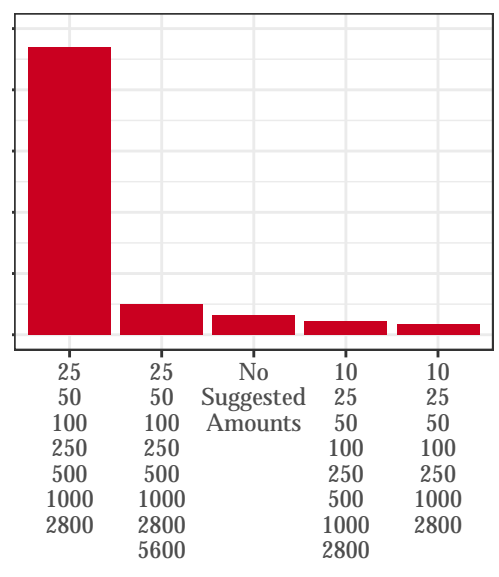

(b) WinRed

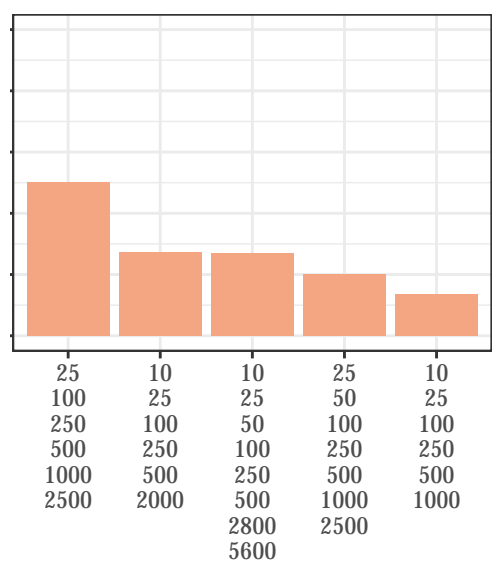

(c) Right.us

Figure 4: Suggested Amounts, Top 5 Sets Per Platform, 2020, All Recipients Per Platform

This indicates that platforms are likely introducing a default set of amounts to a new fundraiser. ${ }^{7}$ For example, Alex Padilla (D-CA), when he was still U.S. Senator-designate, had two ActBlue referrals from his official campaign website, both displaying 25-100-250-1,000 USD, the modal set of ActBlue. These amounts were in place even before Padilla assumed the seat.

That there is a default set of suggested amounts also explains why among Democrats, 25-100250-1,000 USD was the modal set. However, compared to Republicans, Democratic candidates deviated more from the default, potentially from optimization. Preset amounts are one of the variables that can be tested through ActBlue's internal A/B testing capabilities. What's more, Democrats had a much longer period to experiment with ActBlue donations, which may be why a higher proportion of candidates have deviated from what ActBlue initially suggests. ${ }^{8}$

\section{Adjusting to Increased Individual Contribution Limits}

\begin{tabular}{lllll}
\hline & Dem (Senate) & Rep (Senate) & Dem (House) & Rep (House) \\
\hline Adjusted \$2,800 to \$2,900 & 70.6 & 85.7 & 71.9 & 89.3 \\
Did Not Adjust \$2,800 Maximum & 29.4 & 14.3 & 28.1 & 10.7 \\
\hline
\end{tabular}

Table 4: Proportion of Congressional Incumbents that Adjusted for Increased Individual Contribution Limits By Sep 2021

The results above suggest that the behavior of platforms has the potential to affect campaigns' demand-side behavior, which then has the potential to alter how individual contributors give. Here, I provide another piece of relevant evidence on how platforms may affect campaign tactics.

\footnotetext{
${ }^{7}$ This was confirmed for ActBlue via personal correspondences with its personnel. I have not yet been able to officially verify the same for WinRed.

${ }^{8}$ It could also be the case that WinRed's defaults are universally optimal for Republican candidates.
} 
On Feb 2, 2021, the FEC announced an increase in the individual contributor's donation capacity from $\$ 2,800$ to $\$ 2,900$ for candidate committees. Such change is a regular activity per a few election cycles to adjust for inflation per the BCRA (52 U.S. Code $\S 30116(\mathrm{a})(1)(\mathrm{A})$ ). If a candidate previously had $\$ 2,800$ as one of the suggested amounts, it makes sense to make an immediate adjustment to the $\$ 2,900$. It is not a change that is likely to cause attrition for the candidates' potential donors. After all, the marginal difference perceived difference between $\$ 2,800$ and $\$ 2,900$ might not be as extreme as a change in, for example, $\$ 1,000$ to $\$ 2,900$, which may disparage donors from giving. However, it will likely cause a donor who can and is willing to immediately max out to only give $\$ 2,800$, which is $3.5 \%$ less than the full, optimal elicitation.

Did candidates take advantage of this increased donation? Not everyone immediately took notice or made adjustments accordingly. Table 4 shows the proportion of candidates that adjusted by level of race and by party. Each number is a proportion calculated by column: for example, $81.0 \%$ of Republican Senators who had $\$ 2,800$ as one of their suggested amounts switched to $\$ 2,900$ during Feb 2021, whereas only 58.8\% of Democratic Senators did. The difference is just as stark within House incumbents. ${ }^{9}$ Figure 5 shows the over-time adjustments in line graphs. Clearly, Republicans have adjusted much faster, and the gap remains large, although decreasing.

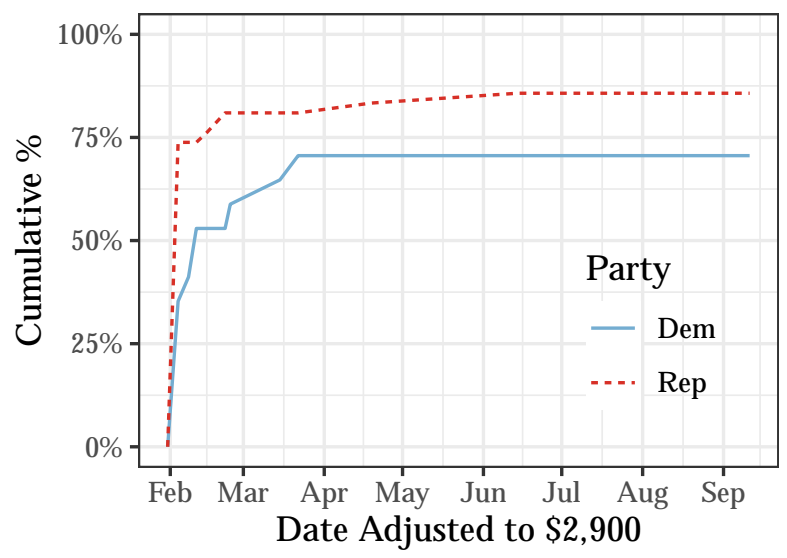

(a) Senate

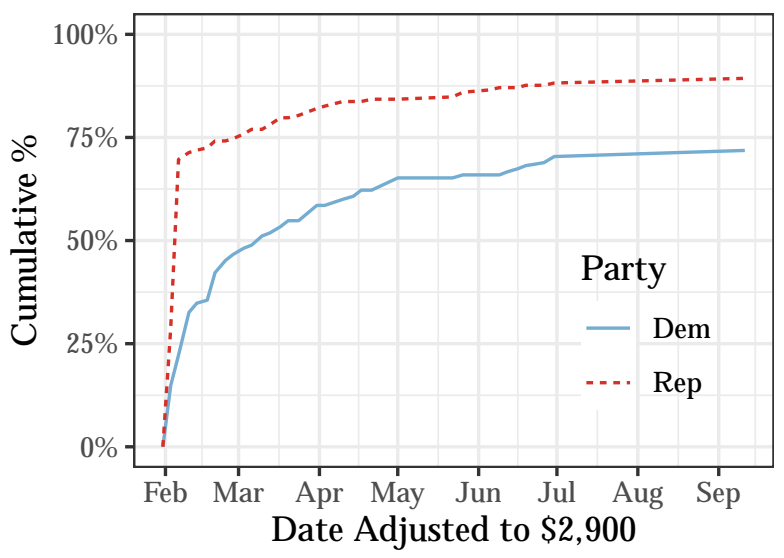

(b) House

Figure 5: Cumulative Percentage of Congressional Incumbents that Adjusted for Increased Individual Contribution Limits, By Race and Party

\section{Party Effect vs. Platform Effect}

Did Republican Candidates Adjust Regardless of the Platform? Given that I have described WinRed as an indirect branch of the Republican Party, one may wonder whether this is a party effect or a platform effect. Perhaps it is the case that the Republican Party or its incumbents were, overall, paying more attention, given that they have more to gain from adjusting? Did

\footnotetext{
${ }^{9}$ Note that the number of Democratic incumbents using $\$ 2,800$ as a suggested amount is much lower than for Republicans.
} 
all Republicans end up adjusting for the increased campaign contribution limit regardless of the platform due to a top-down management tactic from the party?

This is a valid objection, but there is a distinct platform effect. Figure 5 shows each party's congressional incumbents (both Senate and House) by platforms to show how fast they are adjusting to the new maximum. Table 5 shows the distribution of proportions within each type of race and party. For example, 66.7\% of Republican Senators both used WinRed and adjusted to $\$ 2,900$. Conditional on using WinRed, almost all Republican incumbents have adjusted, and very quickly, almost all within the week of the FEC announcement. Republicans that used other platforms adjusted at much lower percentages.

\begin{tabular}{lll|ll|ll|ll} 
& \multicolumn{2}{c}{ Dem (Senate) } & \multicolumn{2}{c}{ Rep (Senate) } & \multicolumn{2}{c}{ Dem (House) } & \multicolumn{2}{c}{ Rep (House) } \\
& ActBlue & Other & WinRed & Other & ActBlue & Other & WinRed & Other \\
\hline Adjusted $\$ 2,800$ to $\$ 2,900$ & 64.7 & 5.9 & 69.0 & 16.7 & 57.8 & 14.1 & 61.8 & 27.5 \\
Did Not Adjust $\$ 2,800$ Maximum & 29.4 & 0.0 & 0.0 & 14.3 & 17.8 & 10.4 & 1.1 & 9.6
\end{tabular}

Table 5: Proportion of Congressional Incumbents that Adjusted for Increased Individual Contribution Limits By Sep 2021, By Platform

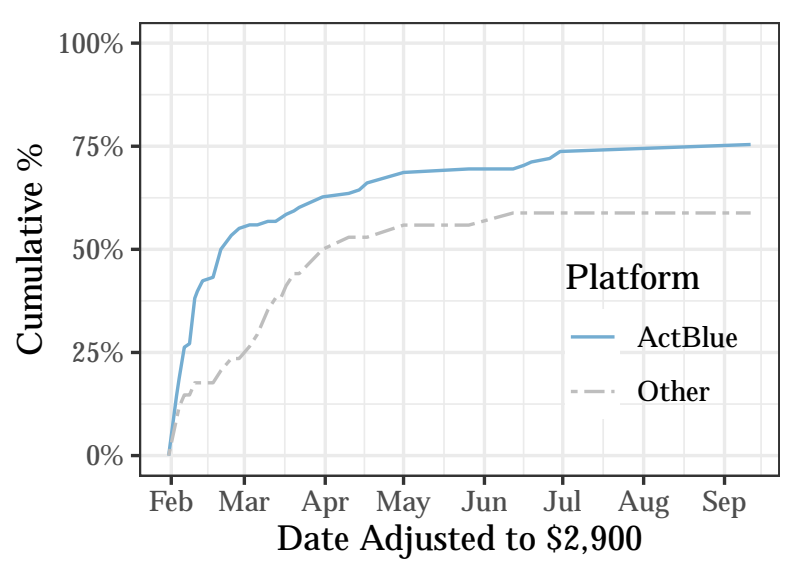

(a) Democrats



(b) Republicans

Figure 6: Cumulative Percentage of Incumbents that Adjusted for Increased Individual Contribution Limits, By Platform within Party, Both Congressional Races

On the Democratic side, conditional on using ActBlue, only three-quarters of Democratic incumbents have pushed up their maximum donation amount. Figure 5 shows that this process was gradual, rather than abrupt as in WinRed's. This seems to suggest that there was a centralized effort from WinRed to make sure that the fundraisers hosted on its pages had changed their limits to $\$ 2,900$. Indeed, the data shows that while WinRed had multiple pages with $\$ 2,800$ on Feb 1, 2021, by Feb 4, they were all changed to $\$ 2,900$.

Another anecdotal evidence that WinRed pushed the change to $\$ 2,900$ can be found from Marjorie Taylor Greene's campaign website (R, GA-14), a freshman incumbent and a staunch ally of 


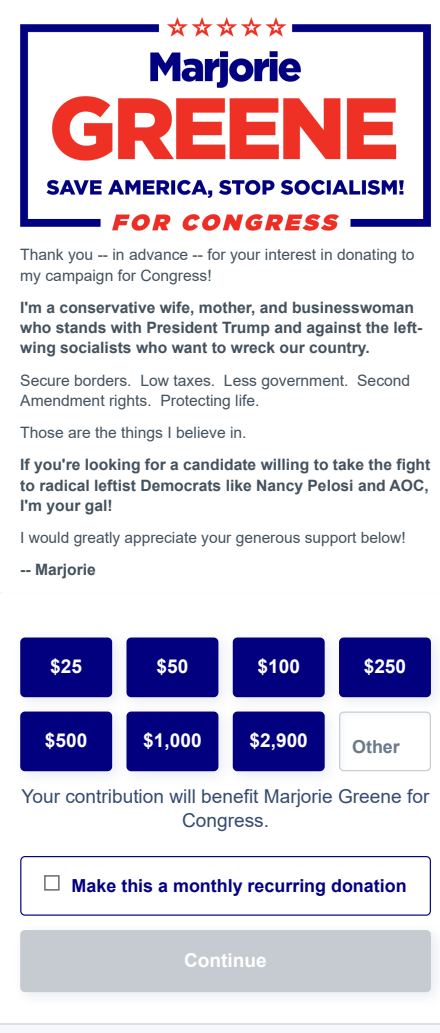

(a) WinRed
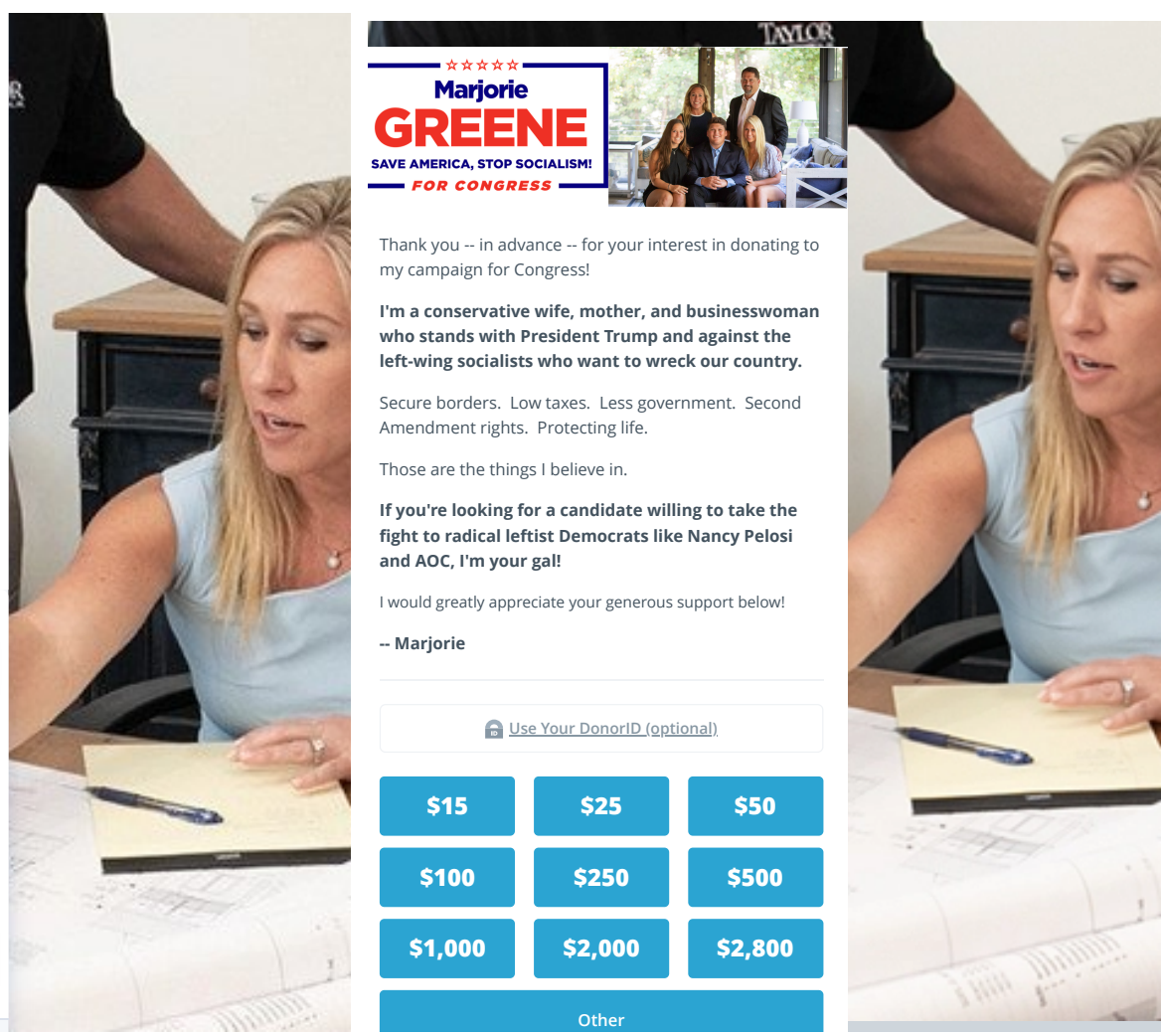

(b) Anedot

Figure 7: Screenshots of Fundraisers Hosted on WinRed and Anedot for Marjorie Greene (R, GA-14), Both Referred from Her Official Campaign Website, Mar 1, 2021

former President Trump. Her campaign website hosts both a WinRed link and an Anedot link as of present, displayed in Figure 7. Even though the pages were (1) for the same candidate, (2) referred officially by the candidate website, and (3) compared at the same time, WinRed's page shows having adjusted to $\$ 2,900$, and Anedot's page not.

This is an interesting example because the only difference between the two links is the platform used and where the referral URL is embedded in the campaign site. ${ }^{10}$ Even if these differences have strong behavioral implications for potential donors, suppose the campaign had the attention span to change the WinRed fundraiser page. It does not seem too difficult to have changed the Anedot page in tandem. This seems to show, indirectly, that it is the platform that is driving the efficiency adjustment, not the candidate/party. Nor is it campaign consultants that can influence a local group of candidates (Nyhan and Montgomery, 2015).

Taking all pieces of the evidence together, they hint at a bigger picture-that the preset amounts themselves are influenced by defaults suggested from platforms. Depending on the situation, this manifests as either efficient or inefficient management of online fundraiser pages. This

\footnotetext{
${ }^{10}$ WinRed link is at the right-top corner "donate" tab, while the Anedot link is at the center-bottom "donate" button.
} 
also explains why there were significantly more Democratic candidates that used $\$ 2,700$ in their suggested amounts in 2020, which again is an inefficient choice for the given election cycle.

This is not to suggest that particular platforms have mismanaged their fundraisers. The difference stems from the aforementioned asymmetry: ActBlue is a mature, decentralized, and open platform that leaves optimization up to individual fundraising entities; WinRed is both new and a centralized platform with the party likely to be heavily involved in its operations. The results demonstrate both this asymmetry and that platforms should not be regarded as passive vehicles of fundraising. Digital fundraising platforms are, in fact, active entities, and how they operate differently has implications for campaign management.

Such leverage that platforms have on campaigns has a real possibility to spill over into contributor behavior. With the storming of the Capitol on Jan 6, 2021, and the second impeachment trial of Trump that began on Feb 9, 2021, partisan animosity was running high. Therefore, there was a possibility that candidates of either party could have benefited from donation spikes in February. Since the FEC increased the contribution limit before the second impeachment trial, the degree to which platforms helped campaigns optimize could have affected the sum of individual contributions received. I leave this test to future research.

The Party as the Latent Variable. One caveat is that one could also say that the coordinated increase of the WinRed users is still, ultimately, a party effect. The Republican Party has chosen to mass-migrate its candidates to WinRed for positive externalities and economies of scale (Kim and Li, 2021). Given that the party is discouraging its candidates from using other platforms, offering better fundraising strategies on WinRed could be a form of selective incentives and a punishment to non-compliers. This is, at the moment, difficult to parse out.

However, this means that, at least for the Republican side, monitoring WinRed is also useful for gaining insight into the leadership and direction of the GOP. For scholarship on political parties, this shows that WinRed can be a means to strategic party coordination (Hassell, 2017).

\section{Conclusion}

In this paper, I have shown that what amounts political campaigns ask as contributions is both an interesting campaign behavior and essential demand-side data that fills in the gaps in the campaign finance literature. Using data collected on (1) online fundraiser pages that 2020 U.S. congressional candidates hosted on their campaign websites and (2) pages hosted on prominent fundraising platforms' directories, I establish benchmark descriptives on what campaigns choose as their suggested amounts to prompt donors to give more.

The choice of suggested amounts in political solicitations varies widely depending on the electoral characteristics and fundraising environments, such as party, state-level average income, and the choice of the fundraising platform. In particular, I show that digital fundraising platforms 
are not merely a medium through which candidates and committees host their fundraiser pages. The default set of suggested amounts that platforms choose has a strong anchoring effect on individual campaign behavior. Moreover, when the FEC increased the donation limit of individual contributors from $\$ 2,800$ to $\$ 2,900$ in 2021 , almost all Republican candidates that used WinRed immediately adjusted their fundraiser pages, while Democratic candidates or candidates that used other platforms adjusted slowly and at much lower levels. This prevented some candidates from taking full advantage of the increased donation limit.

The platforms' behaviors, shaped by their origin and nature, impact campaigns' behaviors—that is to say, how campaigns manage their fundraiser pages can vary by what platform they use. This can, ultimately, create changes in contributor behaviors that are more subtle to detect. All in all, the benchmark results in this paper suggest that the campaign finance ecosystem is multilayered, and there is much room for research to correct omitted variable biases, especially the demand-side of individual contributions that can shape individual contributor behavior and the aggregate cash influx.

The first natural question is whether the strong platform-level tactic observed on the Republican side is an independent decision on the platform-level without an influence of party elites, or the party's tactic that rewards only a group of candidates. At the moment, it is still unclear. Again, if we take the recent definitions of political parties (Koger et al., 2010; Bawn et al., 2012), the boundaries between the two may be blurred - the ownership of WinRed itself could be regarded as part of the party, in the sense that it is a group in the informal party network.

The other next natural questions is: how much do those suggested amounts actually sway individual campaign contributions? Do donations match the patterns seen by the suggested amounts on official campaign sites? A word of caution is that there is no straightforward way to assess the causal effects, as the choices are nonrandom. This prevents us from evaluating the full optimality of the campaign's choices and doing a welfare analysis for the donors. Ideally, it would take a field experiment to do such an assessment, implemented across many campaigns in various levels and types of races, which is not a logistically easy task.

Nevertheless, it is an essential set of questions to ask. For example, do typically small and large donors respond differently to a given set of suggested amounts? Do smaller or larger defaults help generate more repeat donors? Are defaults more effective in attracting first-time donors? Does it all depend on donor demographics or partisan affiliation? Are platforms taking full advantage of these findings? The money in politics literature has much to catch up, compared to the charitable donation literature. What's more, given that platforms are more active players in the campaign finance ecosystem, the effect of platforms on the overall candidate- and party-level fundraising also needs to be analyzed. I leave these for future research. 


\section{References}

Alvarez, R. Michael, Jonathan N. Katz, and Seo-young Silvia Kim (2020). Hidden Donors: The Censoring Problem in U.S. Federal Campaign Finance Data. Election Law Journal: Rules, Politics, and Policy 19(1), 1-18.

Baldwin-Philippi, Jessica (2015). Using Technology, Building Democracy: Digital Campaigning and the Construction of Citizenship. Oxford University Press.

Barber, Michael, Brandice Canes-Wrone, and Sharece Thrower (2019). Campaign Contributions and Donors' Policy Agreement with Presidential Candidates. Presidential Studies Quarterly 49(4), 770-797.

Barber, Michael J., Brandice Canes-Wrone, and Sharece Thrower (2017). Ideologically Sophisticated Donors: Which Candidates Do Individual Contributors Finance? American Journal of Political Science 61(2), 271-288.

Bawn, Kathleen, Martin Cohen, David Karol, Seth Masket, Hans Noel, and John Zaller (2012). A Theory of Political Parties: Groups, Policy Demands and Nominations in American Politics. Perspectives on Politics 10(3), 571-597.

Bonica, Adam (2011). Small Donors and Polarization.

Canes-Wrone, Brandice and Kenneth M. Miller (2021). Out-of-District Donors and Representation in the US House. Legislative Studies Quarterly.

Cigler, Allan (2011). Interest Groups and the Financing of the 2008 Elections. In D. B. Magleby and A. Corrado (Eds.), Financing the 2008 Election, pp. 249-289. Washington, DC: Brookings Institution Press.

Culberson, Tyler, Michael P. McDonald, and Suzanne M. Robbins (2019). Small Donors in Congressional Elections. American Politics Research 47(5), 970-999.

Fenno, Richard F. (1978). Home Style: House Members in Their Districts. Longman.

Francia, Peter L., John C. Green, Paul S. Herrnson, Clyde Wilcox, and Lynda W. Powell (2003). The Financiers of Congressional Elections: Investors, Ideologues, and Intimates. Columbia University Press.

Gimpel, James G., Frances E. Lee, and Shanna Pearson-Merkowitz (2008). The Check Is in the Mail: Interdistrict Funding Flows in Congressional Elections. American Journal of Political Science 52(2), 373-394.

Goldmacher, Shane (2021a, July). Four States Start Inquiries Into Recurring Donation Tactics of Both Parties. The New York Times. 
Goldmacher, Shane (2021b, August). Trump's Repeating Donation Tactics Led to Millions in Refunds Into 2021. The New York Times.

Hassell, Hans J. G. (2017). The Party's Primary: Control of Congressional Nominations. Cambridge University Press.

Hassell, Hans J. G. and J. Quin Monson (2014). Campaign Targets and Messages in Direct Mail Fundraising. Political Behavior 36(2), 359-376.

Heerwig, Jennifer A. (2016). Donations and dependence: Individual contributor strategies in house elections. Social Science Research 60, 181-198.

Helman, Scott (2007, August). Internet-based PAC driving Democratic push. Boston Globe.

Herrnson, Paul S. (2009). The Roles of Party Organizations, Party-Connected Committees, and Party Allies in Elections. The Journal of Politics 71(4), 1207-1224.

Herrnson, Paul S and Stephanie Perry Curtis (2011). Financing the 2008 Congressional Elections. In D. B. Magleby and A. Corrado (Eds.), Financing the 2008 Election, pp. 166-209. Washington, DC: Brookings Institution Press.

Hindman, Matthew (2005). The Real Lessons of Howard Dean: Reflections on the First Digital Campaign. Perspectives on Politics 3(1), 121-128.

Isenstadt, Alex (2019, January). Exclusive: GOP reaches landmark agreement to juice small-dollar fundraising. POLITICO.

Karpf, David (2012). The MoveOn Effect: The Unexpected Transformation of American Political Advocacy. Oxford University Press.

Karpf, David (2013). The Internet and American Political Campaigns. The Forum 11(3), 413-428.

Karpf, David (2016a). Analytic Activism: Digital Listening and the New Political Strategy. Oxford University Press.

Karpf, David (2016b). The Partisan Technology Gap. In Civic Media: Technology, Design, Practice, pp. 199. MIT Press.

Keena, Alex and Misty Knight-Finley (2019). Are Small Donors Polarizing? A Longitudinal Study of the Senate. Election Law Journal: Rules, Politics, and Policy 18(2), 132-144.

Kim, Seo-young Silvia and Zhao Li (2021). Keep Winning with WinRed? Digital Fundraising Platform as the Party's Public Good.

Koger, Gregory, Seth Masket, and Hans Noel (2010). Cooperative Party Factions in American Politics. American Politics Research 38(1), 33-53.

Kreiss, Daniel (2016). Prototype Politics: Technology-intensive Campaigning and the Data of Democracy. Oxford University Press. 
Kreiss, Daniel (2019). Digital opportunity structures: Explaining variation in digital mobilization during the 2016 democratic primaries. In M. X. Delli Carpini (Ed.), Digital Media and Democratic Futures, pp. 42-68.

Magleby, David B., Jay Goodliffe, and Joseph A. Olsen (2018). Who Donates in Campaigns?: The Importance of Message, Messenger, Medium, and Structure. Cambridge University Press.

Malbin, Michael J. (2013). Small Donors: Incentives, Economies of Scale, and Effects. The Forum 11(3).

McCabe, Brian J. and Jennifer A. Heerwig (2019). Diversifying the Donor Pool: How Did Seattle's Democracy Voucher Program Reshape Participation in Municipal Campaign Finance? Election Law Journal: Rules, Politics, and Policy 18(4), 323-341.

Miller, Joanne M., Jon A. Krosnick, Allyson Holbrook, Alexander Tahk, and Laura Dionne (2016). The Impact of Policy Change Threat on Financial Contributions to Interest Groups. In J. A. Krosnick, I.-C. A. Chiang, and T. H. Stark (Eds.), Political Psychology: New Explorations. Routledge.

Nyhan, Brendan and Jacob M. Montgomery (2015). Connecting the Candidates: Consultant Networks and the Diffusion of Campaign Strategy in American Congressional Elections. American Journal of Political Science 59(2), 292-308.

Pildes, Richard H. (2019). Small-Donor-Based Campaign-Finance Reform and Political Polarization. Yale Law Journal Forum 129, 149.

Saul, Stephanie and Rachel Shorey (2019, January). Republicans Seek to Boost Small Donations, but a Fragmented System Stymies Them. The New York Times.

Smith, Ben (2010, October). The right, online. POLITICO.

Tam Cho, Wendy K and Brian J Gaines (2007, August). Breaking the (Benford) Law: Statistical Fraud Detection in Campaign Finance. The American Statistician 61(3), 218-223. Publisher: Taylor \& Francis.

Vogel, Kenneth P. (2007, August). GOP upstarts vie to beat Dems online. POLITICO.

Vogel, Kenneth P. and Darren Samuelsohn (2016, June). Trump's secret data reversal. POLITICO.

Vogel, Kenneth P. and Ben Schreckinger (2016, May). Trump campaign eyes \#NeverTrump blacklist. POLITICO.

Willis, Derek (2014, October). How ActBlue Became a Powerful Force in Fund-Raising. The New York Times. 